\title{
INCORPORATING AFFIRMATIVE ACTION INTO THE WELFARE STATE
}

\author{
TOMER BLUMKIN \\ YORAM MARGALIOTH \\ EFRAIM SADKA
}

CESIFO WORKING PAPER No. 2003

CATEgOry 1: Public FinANCE

MAY 2007

Presented at CESifo Area Conference on Public Sector Economics, April 2007

An electronic version of the paper may be downloaded

- from the SSRN website:

wWw.SSRN.com

- from the RePEc website:

Www.RePEc.org

- from the CESifo website:

www.CESifo-group.de 


\title{
INCORPORATING AFFIRMATIVE ACTION INTO THE WELFARE STATE
}

\begin{abstract}
In this paper, we discuss a novel aspect of affirmative action policy. We examine its redistributive role, asking whether in an egalitarian society, supplementing the tax-transfer system with an affirmative action policy would enhance social welfare.
\end{abstract}

JEL Code: H2, D6.

Keywords: affirmative action, optimal taxation, tagging.

\author{
Tomer Blumkin \\ Department of Economics \\ Ben-Gurion University \\ Beer-Sheba 84105 \\ Israel \\ tomerblu@bgumail.bgu.ac.il
}

\author{
Yoram Margalioth \\ The Buchman Faculty of Law \\ Tel Aviv University \\ Tel Aviv 69978 \\ Israel \\ margalio@post.tau.ac.il
}

\author{
Efraim Sadka \\ The Eitan Berglas School of Economics \\ Tel Aviv University \\ Tel Aviv 69978 \\ Israel \\ sadka@post.tau.ac.il
}

January 2007

The authors wish to thank Alan Auerbach, Oren Bar-Gil, Roger Gordon, Eytan Sheshinski, Hans Werner-Sinn, Jay Wilson and participants in Tel Aviv Economics faculty seminar, a conference organized by the Tel Aviv University School of Economics in honor of the third author's 60th birthday, the ALEA conference in Berkeley and the ELEA conference in Madrid for helpful comments. 


\section{Introduction}

Affirmative action policy regulates the allocation of limited opportunities in education, employment, business contracting, credit, public housing, and the like, to increase the representation of persons belonging to certain population subgroups (Fryer and Loury, 2005).

The main strand in the economic literature on affirmative action focuses on efficiency, examining the potential role of affirmative action in correcting market failures (eliminating discrimination or internalizing externalities). The seminal paper in this literature is Coate and Loury (1993), which examines whether affirmative action eliminates employers' negative stereotypes about the capabilities of minority employees that result in under-investment in human capital by the latter.

However, affirmative action also bears controversial equity implications as it redistributes across racial/ethnic population groups. Contrary to the more passive practice, non-discrimination, in which the normative principle is simply to refrain from treating people differently on the basis of race or other protected characteristics, affirmative action actively offers particular groups, thought to need special treatment, preferential access to important social resources. The public associates nondiscrimination with the universally praised norm of equal opportunity, while generally disparaging preferences as a demand for equal outcomes or special treatment (Schuck, 2002). ${ }^{1}$ As a result, affirmative action has never had much public support. The vast

\footnotetext{
1 The public disconcert is somewhat mitigated by calling for "greater outreach" to minority communities and talking about "preferential boosts," "goals and timelines" instead of imposing quotas or using the term "preferences." However, closer examination reveals that under a plausible assumption of imperfect
} 
majority of Americans, including more than a third of blacks, oppose racial preferences in hiring and promotion (Schuman et al., 1997).

In this paper, we offer a fresh look at the redistributive question, by bringing to the table a different justification for the use of affirmative action as a redistributive device. Instead of analyzing it merely as a tool designed to redistribute across population groups (e.g., from whites to blacks), we establish a case for supplementing the redistributive tax-transfer system by affirmative action to enhance redistribution across skills (rather than across groups), relying on a correlation between earning ability and ethnicity/race.

The existence of such a correlation is supported by advocates of affirmative action, who seek to justify affirmative action as a forward-looking and remedial tool addressing a significant gap in skills between blacks and whites, the outcome of more than two hundred years of discrimination (Sunstein, 1994). According to these advocates, racial inequality today is mostly driven by the supply-side of the labor market rather than the demand side (prejudice), thus calling for something more than only the prevention of discrimination (Loury, 1998; Arrow, 1998). The gap in skills is a reflection of social and cultural factors, such as geographic segregation (see Loury, 1977); deleterious social

information regarding employers' desires to discriminate and the fraction of qualified minorities who applied for each firm, there is no difference between greater outreach or goals, and a quota (Fryer, 2004). Hence, greater outreach is translated into redistribution of jobs and educational resources from members of the majority group to minorities. For example, employers who wish to avoid disparate impact discrimination claims (that is, comply with antidiscrimination laws), make sure that targeted group members are adequately represented among their hires, leading in essence to an affirmative action quota effect. 
norms and peer influences; and poor educational quality. Moreover, each individual is socially situated, and one's location within the network of social affiliations substantially affects one's access to various resources. It has been well established that an individual's inherited social situation plays a major role in determining ultimate economic success (Loury, 1998).

It should be emphasized that we are not arguing that race-based discrimination has been fully eliminated. To the extent that it exists, affirmative action may be viewed as an additional tool in the arsenal of anti-discrimination laws. However, to the extent that it redistributes beyond what is necessary to correct for discrimination, it is a purely redistributive device. This latter function of affirmative action is the focus of this paper.

The remainder of the paper proceeds as follows. In section 2, we present our model. In section 3, we examine the case for affirmative action. Section 4 extends the model to allow for redistribution across groups. In section 5, we conclude.

\section{An Analytical Framework}

Consider an economy with a population equally divided between 'tall' $(j=T)$ and 'short' $(j=S)$ individuals. ${ }^{2}$ We normalize the population of each type to unity. Each individual (tall or short) may be either high-skilled $(i=H)$ or low-skilled $(i=L)$. We assume that production technology exhibits constant returns to scale and perfect substitution across the various skill levels. We denote the productivity (hence the hourly wage rate in an unregulated competitive labor market) of a typical high-skilled individual by $\bar{w}$, and that of a typical low-skilled individual by $\underline{w}$, where $\bar{w}>\underline{w}>0$. We further

\footnotetext{
2 'Height' is a general name for an exogenously given observable attribute.
} 
denote by $\alpha_{i, j}$ the number of individuals of skill $i$ and 'height' $j$ in the population. Following the standard Mirrlees (1971) framework, we assume that the skill (earning ability) attribute is observed by both workers and employers, but unobserved by the government. We further assume that $0<\alpha_{H, S}<\alpha_{H, T}<1$, namely, that the tall population is on average more skilled, which may reflect poor early background for the short population group members, possibly attributed to past discrimination driven by prejudice, or self-fulfilling negative stereotypes (statistical discrimination). ${ }^{3}$ Denote by $K_{T}$ (respectively, $K_{H}$ ), an indicator function that takes the value 1 if an individual is tall (respectively, high-skilled) and zero otherwise. Note that the coefficient of correlation between height and skill is given by $r\left(K_{T}, K_{H}\right)=\frac{\alpha_{H, T}-\alpha_{H, S}}{\sqrt{\alpha_{H, T}+\alpha_{H, S}} \cdot \sqrt{2-\alpha_{H, T}-\alpha_{H, S}}}$, which is positive, by assumption. Note also that $\mathrm{r}$ is increasing in $\alpha_{H, T}$ and decreasing in $\alpha_{H, S}$. In particular, at the limits, when $\alpha_{H, T}=\alpha_{H, S}$, there is a zero correlation; whereas when $\alpha_{H, T}=1$ and $\alpha_{H, S}=0$, there is a perfect correlation between being high-skilled and being tall. The assumption regarding a positive correlation between height and skill implies that in an unregulated labor market, short individuals are over-represented (relative to their

\footnotetext{
3 The assumption may plausibly describe the situation of the black minority in the US. The choice of short individuals to be the disadvantaged group is clearly arbitrary, but may be symbolic, as in this paper, we focus on the government's challenge in addressing the issue of vertical equity.
} 
share in the general population) in low paying jobs. ${ }^{4}$ For later purposes, denote by $\alpha_{H}$ and $\alpha_{\mathrm{L}}$, the fraction of high-skilled (respectively, low-skilled) individuals in society.

We assume that all individuals share the same utility. Following Diamond (1998), for simplicity, we adopt a quasi-linear specification:

(1) $\quad U=U(c, l)=c-h(l)$,

where $c$ denotes consumption, $l$ denotes labor and $h$ is increasing and strictly convex. As is common in the optimal tax literature, we denote by $y$ the labor income of an individual, so that $l=y / w$. Thus, we rewrite the utility function of an individual with a wage rate of $w$ as:

(2) $\quad V(w, c, y)=U(c, y / w)$.

We assume that society cares about inequality across skill levels, as is customary in the public finance literature. ${ }^{5}$ For concreteness, we consider an egalitarian social welfare function, which takes the following CES special form:

$$
W=\sum_{i} \alpha_{i} \cdot V_{i}^{\rho} / \rho
$$

where $0 \neq \rho<1$.

In order to address the issue of inequality, the government may consider the use of several redistributive tools. We will examine two such redistributive tools: affirmative action and the income tax-transfer system.

\footnotetext{
${ }^{4}$ There is a substantial Black-White test score gap, which grows throughout the school years. For a recent discussion, see Fryer and Levitt (2004). If minimum wage were imposed, it would imply a higher unemployment incidence among the short population.

${ }^{5}$ In section 4 below, we extend the analysis by incorporating into the social welfare function a preference for re-distribution across height groups.
} 


\subsection{Affirmative Action}

Consider the following simplified form of affirmative action legislation. The law would impose, upon all employers, targets to achieve mixing of tall and short in the workforce that reflects their share in the general population. What we have in mind is the following: One can define a standard job by a fixed number of working hours (say, per week) and require that the distribution of standard jobs would reflect the height distribution in society. To simplify the notation, we normalize the number of hours per standard job to one. Affirmative action policy that focuses on average representation in each firm reflects the fact that the government cannot readily observe individuals' skill levels and thus is unable to regulate jobs according to skill levels (say, by requiring that for each job, given its associated skill level, the short population be represented according to its relative share in the general population). ${ }^{6}$ Whereas the model we introduce, in the spirit of the classic Mirrlees (1971) framework, focuses on the intensive margin; it captures in a reduced form the essential fact that the short population is under-represented in the labor market. ${ }^{7}$

\footnotetext{
${ }^{6}$ This policy is similar to $C A F E$ standards applied in the context of car emissions to regulate the level of pollution, where each car manufacturer is faced with average emission requirements as opposed to permodel restrictions. See Parry \& Portney, Paul \& Harrington, Winston \& Gruenspecht (2003).

${ }^{7}$ One could think of extending the model to allow for a secondary sector (possibly unemployment), where both population groups are faced with equal job opportunities. In such a case, the short population would be under-represented in the primary sector. Such an extension will complicate the analysis without changing the gist of our argument.
} 
By virtue of the constant returns to scale assumption, the number of firms is indeterminate, and we focus our discussion on a representative firm. We characterize the equilibrium in a labor market regulated by affirmative action policy as described above. ${ }^{8}$ We assume that the labor market is perfectly competitive. We first analyze the firm's behavior. Note that by virtue of affirmative action, there can potentially be four different wage rates, as individuals differ on two attributes: skill and height. In particular, this infers difference in wage rates within the same skill level across population groups. ${ }^{9}$ While this is not what we see in reality, because wage discrimination is illegal, it captures in reduced form the inherent discriminating nature of affirmative action policy, which implies, at the bottom line, higher expected remuneration for targeted group members (in each and every skill level). ${ }^{10}$ Preferring short individuals over equally skilled tall individuals in hiring and in promotion is equivalent to offering the short individuals higher expected remuneration.

We denote by $w_{i, j}$ the equilibrium wage rate paid to a typical individual with skill $i$ and height $j$, where $i=H, L$ and $j=T, S$. The representative firm, faced with the market

\footnotetext{
${ }^{8}$ We confine our attention to equilibria with full employment. See, however, footnote 12 below, which addresses the possibility of equilibrium where the low-skilled tall individuals are driven out of the labor market by affirmative action policy.

9 Note, however, that in a labor market with initial discrimination against the short, affirmative action would mitigate the wage difference across 'heights' for each skill level. In essence, affirmative action would then be a form of anti-discrimination policy.

${ }^{10}$ Put differently, affirmative action "will generally lead to an equilibrium in which the targeted applicants of a given skill level enjoy wider job options, more bargaining power and, consequently, greater remuneration than comparable non-targeted applicants" (Fryer and Loury, 2005).
} 
wage rates, determines labor demand for each type of worker $\left(x_{i, j}\right.$, measured in working hours/jobs) by maximizing:

$$
\pi \equiv \sum_{i} \sum_{j} x_{i, j} \cdot\left(z_{i}-w_{i, j}\right)
$$

subject to the affirmative action constraint:

$$
\sum_{i} x_{i, T}=\sum_{i} x_{i, S}
$$

where $z_{H}=\bar{w}$ and $z_{L}=\underline{w}$ denote, respectively, the productivity of a high-skilled (lowskilled) individual. The affirmative action constraint simply states that the aggregate number of standard jobs filled by the two height groups is the same (recall that we assume that the two height groups are of equal size). The maximization yields the firm's labor demand for each type of worker, $x_{i, j}\left(w_{H, S}, w_{L, S}, w_{H, T} w_{L, T}\right) ; i=H, L$ and $j=T, S$. Note that the demand for each type of worker depends on all four wage rates and on the two productivity levels. We henceforth drop the arguments of the functions $x_{i, j}(\cdot)$ in order to abbreviate the notation.

Individuals determine their labor supply by maximizing the utility in (2) given the market wage rates. We denote by $l(w)$ the labor supply of an individual facing a wage rate of $w$. Note that, by virtue of our assumptions on the utility function, the labor supply is upward sloping. Market clearance requires that demand equal supply for each type of worker, that is:

$$
\begin{aligned}
& x_{H, T}=\alpha_{H, T} \cdot l\left(w_{H, T}\right), \\
& x_{H, S}=\alpha_{H, S} \cdot l\left(w_{H, S}\right), \\
& x_{L, T}=\left(1-\alpha_{H, T}\right) \cdot l\left(w_{L, T}\right), \\
& x_{L, S}=\left(1-\alpha_{H, S}\right) \cdot l\left(w_{L, S}\right) .
\end{aligned}
$$


We now turn to characterizing the equilibrium profile of wage rates. First, note that by virtue of the affirmative action constraint in (5), a necessary condition for equilibrium to exist would be the following:

$$
\bar{w}-w_{H, S}=\underline{w}-w_{L, S} .
$$

To see this, note that the expression on the left side of equation (7) represents the net gain (for the firm) per hour (or job) worked by a high-skilled short individual. Similarly, the expression on the right side of equation (7) represents the net gain per hour worked by a low-skilled short individual. By way of contradiction, suppose that equilibrium exists where the equality in equation (7) is violated. With no loss of generality, let the net gain from an hour worked by a high-skilled short worker be greater than the net gain derived from an hour worked by a low-skilled short worker. In such a case, the firm can replace one working hour of a low-skilled short worker with that of a high-skilled short worker, increasing its profit without violating the affirmative action constraint. ${ }^{11}$ Thus, we obtain a contradiction to the presumed profit maximization. An analogous argument for tall individuals implies that in equilibrium:

$$
\bar{w}-w_{H, T}=\underline{w}-w_{L, T} \cdot{ }^{12}
$$

${ }^{11}$ Recall that such a shift is feasible, as we focus on equilibria in which all types of workers are employed.

${ }^{12}$ While we choose to focus on the case of full employment equilibrium, equilibria where some individuals are driven out of the labor market may also exist. For example, there may exist an equilibrium where the low-skilled tall are offered a zero wage rate and therefore choose to stay out of the labor market. In such a case, the equality in (8) may turn into a strict inequality: $\bar{w}-w_{H, T}>\underline{w}$. Note that, as the firm does not hire the labor services of low-skilled tall individuals in such a case, it cannot raise its profits by replacing lowskilled tall workers with high-skilled tall ones. 
Finally, a necessary condition for equilibrium to exist is that the following equality holds:

$$
\bar{w}-\left(w_{H, S}+w_{H, T}\right) / 2=0 .
$$

Condition (9) requires that an increase (or decrease) in the number of hours worked by both a high-skilled tall and a high-skilled short worker (so that the affirmative action constraint is maintained) cannot affect the firm's profit. Otherwise, if the sign of (9) is positive (negative), the firm can increase its profits by increasing (decreasing) the number of working hours of both the high-skilled tall and short individuals. A similar condition holds for low-skilled individuals:

$$
\underline{w}-\left(w_{L, S}+w_{L, T}\right) / 2=0 .
$$

(Note, however, that one of the four conditions, (7)-(10), is redundant).

Substituting for the labor demands from the equations in (6) into the affirmative action constraint in (5), the equilibrium is given by the profile of wage rates ( $w_{i, j} ; i=H, L ; j=T, S$ ) that solve equations (5), (7), (8) and (9). Employing equations (9) and (10), we set $w_{H, S}=\bar{w}+\varepsilon, w_{H, T}=\bar{w}-\varepsilon, w_{L, S}=\underline{w}+\delta$ and $w_{L, T}=\underline{w}-\delta$. Note that it follows from equation (7) that $\varepsilon=\delta$. It is also worth noting that the representative firm makes zero profits. ${ }^{13}$

We next show that a unique equilibrium exists and that $\varepsilon$ is strictly positive. Substituting the four labor demands into the affirmative action condition in (5) yields:

\footnotetext{
13 To see this, note that substituting the four wage rates into the profit function in (4), re-arranging terms, yields: $\pi=\varepsilon \cdot\left(x_{H, T}-x_{H, S}\right)-\delta \cdot\left(x_{L, S}-x_{L, T}\right)$. Employing the affirmative action constraint in (5), one can rewrite the profit function as follows: $\pi=x \cdot(\varepsilon-\delta)$, where $x \equiv x_{H, T}-x_{H, S}=x_{L, S}-x_{L, T}$. The result follows as $\varepsilon=\delta$.
} 
$L_{T}(\varepsilon) \equiv \alpha_{H, T} \cdot l(\bar{w}-\varepsilon)+\left(1-\alpha_{H, T}\right) \cdot l(\underline{w}-\varepsilon)=\alpha_{H, S} \cdot l(\bar{w}+\varepsilon)+\left(1-\alpha_{H, S}\right) \cdot l(\underline{w}+\varepsilon) \equiv L_{S}(\varepsilon)$,

where $L_{j}(\varepsilon)$ denotes the aggregate labor supply of individuals of height $j=T, S$. It is straightforward to verify that in the absence of wage differences among individuals with the same skill (that is, $\varepsilon=0$ ), the aggregate labor supply of the tall individuals would exceed that of the short individuals: $L_{T}(0)>L_{S}(0)$. Moreover, setting $\varepsilon=\underline{w}$, it follows that: $\lim _{\underline{w} \rightarrow-}^{-}\left[L_{T}(\underline{w})\right]=0<\lim _{\underline{w} \rightarrow-}^{-}\left[L_{S}(\underline{w})\right]$. Thus, when the productivity difference across skill levels is sufficiently small (namely, $\underline{w}$ is sufficiently large), $L_{T}(\underline{w})<L_{S}(\underline{w})$, hence, by continuity considerations, a solution for $\varepsilon$ (hence equilibrium) exists, where $0<\varepsilon<\underline{w}$. Moreover, $\varepsilon$ is unique because the labor supply function is strictly increasing. It is straightforward to verify that equation (8) is satisfied, thus all equilibrium conditions [(5), (7), (8), (9) and the zero profit condition] are satisfied. This concludes the characterization of the equilibrium in the labor market with affirmative action.

As expected, in order to induce higher participation of short individuals in the labor market, employers offer them a higher wage rate relative to tall individuals with the same skill. The wage difference (for each skill level) is given by $2 \varepsilon>0$. By fully differentiating equation (11) with respect to $\alpha_{H, T}$, one can verify that the wage difference is increasing with respect to the proportion of high-skilled tall individuals. Similarly, the wage difference is decreasing with respect to $\alpha_{H, S}$, the proportion of high-skilled short individuals. Finally, it can be verified, by fully differentiating equation (11), taking the limit at $\underline{w} \rightarrow \bar{w}$, and noting that in this limiting case $\varepsilon \rightarrow 0$, that the wage difference is 
decreasing with respect to $\underline{w}$ when the productivity difference across skill levels is sufficiently small.

We next consider a redistributive income tax-transfer system.

\subsection{An Income Tax}

Unlike the standard optimal income tax framework, where the source of inequality derives from unobserved variation in innate earning abilities, the height characteristic is both observable and immutable. One could, in principle, implement a height-sensitive system. In such a case, each short individual would be eligible for a transfer from the state, for example, through refundable credit. ${ }^{14}$ This transfer would be financed by a lump-sum tax. Such a policy would entail no deadweight loss. This policy would suffice to eliminate any inequality between height groups or even render preferential treatment to one group over the other. In light of the positive correlation between skill level and height, the latter serves as an extremely efficient 'tagging' device of the low-skilled (as in Akerlof 1978). Notably, when $\alpha_{H, T}=1$ and $\alpha_{H, S}=0$, that is, when there is a perfect correlation between height and skill, such a policy would attain full equality (full redistribution across skill levels), with no distortions being entailed (the "first-best").

Similarly, affirmative action that redistributes from tall to short individuals may also be viewed as a redistributive tool across skill-levels using height as a 'tagging' device. However, unlike the height-sensitive tax-transfer system, it entails significant labor-leisure distortions. For example, in the perfect correlation case, affirmative action

\footnotetext{
${ }^{14}$ Alternately, the tax subsidy could be given to the employers of short individuals.
} 
would also attain full equality, ${ }^{15}$ but it would do so at the cost of labor supply distortions, increasing the labor supply of short individuals and decreasing the labor supply of tall individuals. Hence a height-sensitive income tax system would dominate affirmative action policy, rendering the latter redundant for re-distributive purposes. ${ }^{16}$

Contrary to affirmative action that, although unpopular, has survived politically for four decades, a height-sensitive income tax system would be infeasible politically. Such a tax system would be viewed as allowing the tall to purchase a right to discriminate against the short [see, e.g., Darity and Frank (2003), Bell (1992), Donohue (1998), Kull (1994), cf. Cooter (1994)].

Moreover, a race-based tax system would be held unconstitutional by the courts. Affirmative action, on the other hand, was approved by the courts on many different occasions. Its economic equivalence to taxation has eluded the courts' attention, probably by following the same logic as in Rubenfeld (1997), according to which there is a difference between taking "from whites (or anyone else) something they already have, as opposed to denying them an opportunity for which they are merely applying. ... Thus, standard affirmative action plans would be constitutional, but a special tax levied only on whites or members of any other race would not." Hence, affirmative action is held constitutional, albeit on shaky grounds. A race-sensitive income tax system would not be.

\footnotetext{
${ }^{15}$ In such a case, by virtue of equation (11), the uniform wage rate is given by the average productivity $(\bar{w}+\underline{w}) / 2$.

16 As discussed in the introduction, affirmative action may be warranted on efficiency grounds. These, however, are beyond the scope of this paper.
} 
In what follows, we focus on a second-best 'height-blind' income tax system. As is common in the income tax literature, we describe the tax system as a set of gross labor income-net labor income (consumption) bundles $(y, c)$, where $c$ denotes net labor income. A tax system has to satisfy self-selection constraints, which state that each type of worker has no incentive to mimic the other type. Denote the $(y, c)$-bundle of the high-skilled individuals and that of the low-skilled individuals by $(\bar{y}, \bar{c})$ and $(\underline{y}, \underline{c})$, respectively. A high-skilled individual must be at least as well off with her bundle as with the bundle of the low-skilled individual, and vice-versa. The self-selection constraints are therefore given as follows:

$$
V(\underline{w}, \underline{c}, \underline{y}) \geq V(\underline{w}, \bar{c}, \bar{y}) .
$$

The government seeks to maximize the social welfare function given in (3), subject to self-selection constraints (12) and (13) and a revenue constraint:

$$
\left(\alpha_{H, T}+\alpha_{H, S}\right) \cdot(\bar{y}-\bar{c})+\left(\alpha_{L, T}+\alpha_{L, S}\right) \cdot(\underline{y}-\underline{c}) \geq 0 .
$$

This specification assumes, with no loss in generality, that the government has no revenue needs (a purely re-distributive tax-transfer system).

\section{A Case for Affirmative Action}

We now investigate whether supplementing a second-best height-blind income tax system by affirmative action would enhance social welfare. When affirmative action is in place, there are four different wage rates in the labor market equilibrium. As shown in section 2.1, for each skill level, the wage-differential across 'heights' is given by 
$2 \varepsilon>0$, favoring short individuals. A height-blind income tax system is given by four different $(y, c)$ bundles. The government would seek to maximize the social welfare function by choosing the four bundles and by setting the wage differential, satisfying the 12 self-selection (no-mimicking) constraints ${ }^{17}$ and an affirmative action constraint, which requires that the aggregate number of standard jobs filled by the two height groups is the same. In appendix A, we provide a formulation of the constrained optimization problem faced by the government.

The following proposition states a sufficient condition for affirmative action to be a desirable supplement to the height-blind income tax system.

Proposition: When the degree of aversion to inequality across skill levels is high enough (that is, $\rho$ is sufficiently small ${ }^{18}$ ), supplementing the height-blind income tax system with affirmative action would enhance social welfare when: (i) the correlation between height and skill level is sufficiently high; and (ii) the difference in productivity across skill levels is sufficiently small.

Proof: See appendix B. QED

The main lesson from the above proposition is that affirmative action may be socially desirable as a supplementary redistributive tool to the tax-transfer system. The rationale for the result is the following. Affirmative action would increase the wage rate, hence the well-being, of short individuals at each skill-level, and, correspondingly,

\footnotetext{
${ }^{17}$ Recall that there are four types, where each can pretend to be any of the other three types.

18 Parameter $\rho$ should be bounded away from minus infinity (that is, a Rawlsian government), as in such a case, affirmative action turns out to be harmful and hence undesirable. For further details on this caveat, see appendix B.
} 
decrease the wage rate, hence, the well-being, of tall individuals. Due to the positive correlation between height and skill, affirmative action results in targeting of transfers to the low-skilled ('tagging'). When the correlation is high enough, benefits from redistribution are significant. In particular, in the case of perfect correlation between skill and height, affirmative action would achieve full equality (equal wage rate for all individuals in the economy). This goal could never be attained by the (height-blind) taxand-transfer system due to incentive compatibility constraints [see, e.g., Sadka (1976) and Stiglitz (1982)].

However, affirmative action distorts labor-leisure choices by inducing wage differentials across heights for each skill-level [the wage rate equals productivity for each skill-level only on average; see equations (9) and (10)], in order to increase the wage rates of short individuals and thereby their participation in the labor market. As the productivity difference across skill levels declines the distortion caused by affirmative action policy decreases (as is reflected in reduced wage differentials).

When the government exhibits a sufficiently high degree of inequality-aversion, supplementing the tax-and-transfer system with affirmative action policy would be socially desirable under the conditions stated by the proposition, because the benefits of enhanced redistribution outweigh the costs of distorted labor-leisure choices.

\section{Redistribution across Groups}

The case for affirmative action as a re-distributive tool becomes even stronger, when society cares not only about inequality across skills (within height groups) but also about inequality across height groups (plausibly justified, when the inequality across groups is driven by past discrimination). The Equal Protection Clause in the US 
Constitution can be interpreted as calling for redistribution towards especially disadvantaged groups (apart from individuals), such as blacks, that have suffered from perpetual subordination and circumscribed political power [see Fiss (1976) for the seminal work on this issue]. One simple way to capture the two forms of inequality aversion is by letting the social welfare function assume the following specification:

$$
W=\sum_{j} W_{j}^{\rho_{1}} / \rho_{1}
$$

where $W_{j}=\sum_{i} \alpha_{i, j} \cdot V_{i, j}{ }^{\rho_{2}} / \rho_{2}$ denotes the aggregate welfare measure for population group $j$, and $0 \neq \rho_{1}, \rho_{2}<1$. Parameter $\rho_{1}$ measures the aversion to inequality across heights; whereas parameter $\rho_{2}$ measures the aversion to inequality across skills.

Note that the transfer of one dollar from a high-skilled individual to a low-skilled individual in the same height group increases social welfare. Similarly, the transfer of one dollar from a tall individual to a short one of similar skill also increases social welfare. Further note that our specification of the social welfare function implies that a given level of wage inequality elicits more aversion by society when this inequality stems from a difference in height than a difference in skill. To see this, consider an economy where the population is equally divided between short and tall individuals. Suppose that one-half of the population is low-skilled, whereas the other half is high-skilled. Consider the following two cases. In the first, all the short individuals are low-skilled and all the tall individuals are high-skilled. In the second case, one-half of the short individuals and onehalf of the tall individuals are low-skilled. According to the welfare specification we use, the second case is superior to the first one, although both cases exhibit the same overall 
distribution of income (that is, one-half of the population is low-skilled and one-half is high-skilled).

Although the case for affirmative action seems to be strongest when society assigns a high weight to redistribution across groups, it is nevertheless possible that the (height-blind) tax-transfer system alone can serve this purpose more efficiently. In fact, as we demonstrate below, affirmative action could be harmful even if we assume that society cares only about redistribution across groups and that the degree of aversion towards inequality across groups is extreme.

To see this, consider the following example. We assume that preferences take a quadratic functional form, $U(c, l)=c-l^{2} / 2$. We further assume that $\rho_{1} \rightarrow-\infty$ and $\rho_{2}=1$. Thus, by virtue of the (quasi-linear) utility specification, the only purpose of redistribution is to mitigate inequality across population groups. Finally, we assume that $\alpha_{H, T}=1-\alpha_{H, S}=p>0.5$, thus the degree of correlation is given by $r=(2 p-1)$.

Figure 1 below demonstrates the optimal policy as a function of the two key parameters of the model: the correlation between height and ability, and the difference in productivity across skills. Note that in the numerical solution we allow for the use of both policy instruments (affirmative action and the tax-transfer system) simultaneously. 
Figure 1

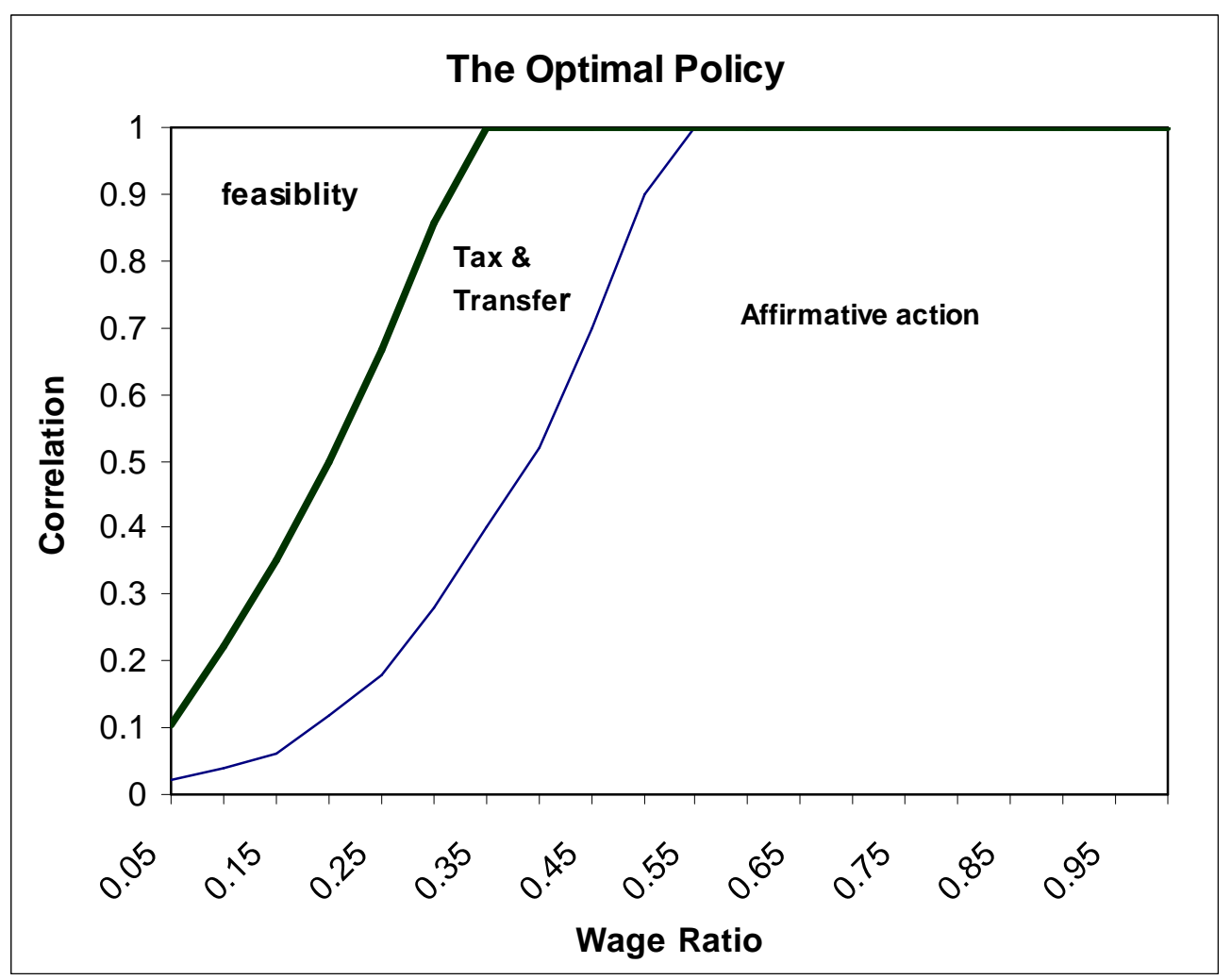

As can be observed from the figure, there are two upward sloping curves, which divide the space into three distinct regions. The uppermost region represents combinations of skill ratio and correlation for which affirmative action equilibrium does not exist. Solving (11) to obtain an explicit solution for $\varepsilon$, employing the quadratic specification, yields $\varepsilon=(2 p-1) \cdot(\bar{w}-\underline{w}) / 2 .{ }^{19}$ The feasibility constraint implies that $\underline{w}>\varepsilon \Leftrightarrow \underline{w} / \bar{w}>(2 p-1) /(2 p+1)$. Thus, as observed from the figure, the weaker the correlation (smaller $p$ ), the less binding the feasibility constraint becomes. The

19 Note that the comparative static results derived for the general framework hold as $\partial \varepsilon / \partial p>0$ and $\partial \varepsilon / \partial \underline{w}<0$. 
intermediate region (labeled 'tax-transfer') represents points in the skill ratio correlation space for which the tax-transfer forms the optimal policy; whereas for points within the rightmost region (labeled 'affirmative action'), affirmative action policy prevails.

Several remarks are in order. First, the optimal policy consists of either an affirmative action policy or an optimal tax-transfer system. This somewhat surprising result derives from the fact that once affirmative action policy is in place, the tax-transfer system is redundant, as the government is assumed to have no taste for redistribution within groups $\left(\rho_{2}=1\right)$, and individuals' preferences are quasi-linear. In general, even when income tax has no redistributive role across skills, it may well serve as a 'tagging' device to enhance redistribution across height groups. However, one can verify that due to the quadratic specification, the welfare aggregates of the two population groups are equalized by affirmative action, hence leaving no re-distributive role for the tax-andtransfer system. Second, as argued above, even though society is assumed to care (extremely) only about inequality across population groups, affirmative action may not be part of the optimal policy. This would happen when the correlation between height and skill is high enough (for a given skill difference). The reason is that when re-distribution across groups is at stake, a high correlation makes the tax-and-transfer system an effective re-distributive tool: although a height-blind tax-and-transfer system cannot directly provide transfers to short individuals, it can do so indirectly by subsidizing lowskilled individuals who are more likely to be short. Moreover, as the correlation between height and skill rises, the distortion of an affirmative action policy increases (an increased wage subsidy to the short and a corresponding increased wage tax levied on the tall, for 
each skill level) to ensure appropriate representation in the labor market; that is, reflecting the groups' relative shares in the general population.

\section{Concluding Remarks}

The primary goal of the welfare system is to target benefits to certain needy populations. This is done either through self-selection of the beneficiaries or by setting eligibility criteria. The efficiency of the welfare system depends on the extent to which individuals' incentives to be identified as 'needy' can be minimized. Indeed, when there is a positive correlation between height (an exogenously given observable attribute) and skill (an exogenously given unobservable attribute), allowing for height-sensitive transfers would enhance redistribution without entailing distortions (as individuals cannot affect their eligibility status - the latter being based on some exogenously given observed characteristic). The fact that a height-sensitive tax-and-transfer system is controversial on moral, political or constitutional grounds renders affirmative action policy a second-best optimal tagging device. We show that affirmative action policy could play a useful redistributive role by supplementing a height-blind income tax system when its entailed distortions are moderate, as it serves to mitigate the incentive compatibility constraints faced by the government in pursuing its redistributive goal.

We further discuss the possibility of extending the standard welfare function by assuming that society cares not only about inequality across skills but also about redistribution across groups. We show that, although the case for affirmative action seems to be the strongest when redistribution across groups is the primary policy objective, affirmative action may well be socially undesirable in such a case. Thus, the social desirability of employing affirmative action policy for redistributive purposes is 
not a foregone conclusion, and will generally depend on the relative weights assigned to the various redistributive concerns, as well as on the correlation between height and skill.

Three final remarks are in order. First, whereas this paper focuses on the redistributive aspects of affirmative action policy, there are two other major justifications, often discussed in the literature: offsetting discrimination (prejudice-driven or statistical) and internalizing externalities.

Second, designing policies that exploit correlations between race and unobserved traits, while generally known to be efficient, is nevertheless controversial. One salient example is the practice of racial profiling in the context of criminal enforcement. Although efficient, racial profiling is often rejected on equity grounds. The equity costs entailed by using racial profiling is not due to the intrinsically discriminating nature of the policy tool (as it is driven by efficiency considerations, that is, minimizing crime, and not by prejudice), but rather due to its expressive nature, when the targeted population has suffered from discrimination on other grounds (see Risse and Zeckhauser, 2004). For example, this would be the case when police target black drivers in drug searches. In our case, as we are discussing welfare policy, the group that has been subject to discrimination is the one that stands to benefit from the profiling/tagging policy proposed. This may somewhat mitigate the equity concerns. That said, even members of groups that have not been discriminated against (the tall individuals), may still find 
affirmative action to be discriminatory. This may explain the use of less efficient forms of affirmative action than the one discussed in this paper, such as height-blind policies. ${ }^{20}$

Finally, in order to mitigate the distortions entailed by affirmative action, one may consider using alternative forms of affirmative action than the one discussed in the current paper. One possibility is to allow for policies aimed at increasing the representation of the targeted groups in the labor market, but to a lesser extent than their relative share in the general population. Another possibility would be to allow for differential targets across occupations; for instance, setting more rigid targets for occupations where productivity differences across skill levels are lower.

\footnotetext{
${ }^{20}$ For example, public university systems in California, Florida and Texas base their admission decisions on social traits that are merely correlated with race instead of taking race explicitly into account. See Chan and Eyster (2003); Fryer, Loury and Yuret (2006).
} 


\section{Appendix A}

\section{Formulation of the Integrated Government Problem}

When affirmative action policy is in place, there are four different wage rates in the labor market, denoted by $w_{i, j}$ where $i=H, L$ and $j=T, S$. A tax-and-transfer system is given by four $(y, c)$ bundles, one for each type of individual. The government seeks to maximize the welfare function given by:

(A1) $W=\sum_{i} \sum_{j} V\left(w_{i, j}, y_{i, j}, c_{i, j}\right)^{\rho} / \rho$

by choosing the four gross income-net income bundles and by setting the wage differential, denoted by $\varepsilon$, subject to 12 self-selection (no mimicking) constraints (three for each type of individual), given by:

(A2) $V\left(w_{i, j}, y_{i, j}, c_{i, j}\right) \geq V\left(w_{i, j}, y_{i^{\prime}, j^{\prime}}, c_{i^{\prime}, j^{\prime}}\right)$, for all $i, j$ and $i^{\prime}, j^{\prime} \neq i, j$;

an affirmative action constraint which requires that short individuals are represented in the labor market according to their relative share in the general population, which is given by:

(A3) $\quad \sum_{i} \alpha_{i, T} \cdot y_{i, T} / w_{i, T}=\sum_{i} \alpha_{i, S} \cdot y_{i, S} / w_{i, S}$

and the firm's profit maximization conditions (under the affirmative action regime), given by:

(A4) $w_{H, T}=\bar{w}-\varepsilon, w_{H, S}=\bar{w}+\varepsilon, w_{L, T}=\underline{w}-\varepsilon$ and $w_{L, S}=\underline{w}+\varepsilon$. 


\section{Appendix B}

\section{Proof of the Proposition}

We prove that under the condition stated in the proposition, affirmative action would dominate the tax-and-transfer system and hence should be part of the optimal policy alongside the tax-and-transfer system.

Suppose that $\rho=-\infty$. Consider the case of perfect correlation between height and skill, that is, $\alpha_{H, S}=0$ and $\alpha_{H, T}=1$.

Recall that in the case of perfect correlation, affirmative action policy fully equalizes the wage rates (hence the income and consumption levels) across all individuals in the economy. We denote the uniform wage rate (equaling the average productivity) by $\hat{w} \equiv(\bar{w}+\underline{w}) / 2$, and the associated income level (hence the consumption level in the absence of taxation) by $\hat{y}$. Denote the welfare measures for the optimal tax system and the affirmative action rule, respectively, by $W^{T a x}$ and $W^{A f f}$. Maintaining the notation used in the text, it follows that:

(B1) $W^{\operatorname{Tax}}=V(\underline{w}, \underline{c}, \underline{y})$,

(B2) $\quad W^{A f f}=V[\hat{w}, \hat{y}, \hat{y}]$,

Note that when $\underline{w}=\bar{w}$, it follows that $\underline{w}=\hat{w}, \underline{\mathrm{c}}=\underline{y}=\hat{y}$ and, obviously, $W^{T a x}=W^{A f f}$, as there is no inequality to begin with. Differentiating the two welfare measures associated with the optimal tax system and the affirmative action rule with respect to $\underline{w}$, and evaluating the derivatives at $\underline{w}=\bar{w}$, using the envelope theorem, and noting the fact that the self-selection constraint for the low-skilled type is non-binding, it follows that: 
(B3) $\left.\frac{d W^{T a x}}{d \underline{w}}\right|_{\underline{w}=\bar{w}}=U_{c}(\bar{c}, \bar{y} / \bar{w}) \cdot \frac{\bar{y}}{\bar{w}}>\left.\frac{d W^{A f f}}{d \underline{w}}\right|_{\underline{w}=\bar{w}}=U_{c}(\bar{c}, \bar{y} / \bar{w}) \cdot \frac{\bar{y}}{\bar{w}} / 2$.

where $U_{c}=1$ by virtue of the quasi-linear utility specification. Thus, it follows, by virtue of a first-order approximation, that for $\underline{w}$ close enough to $\bar{w}$, the affirmative action rule attains a higher level of welfare than the optimal tax system. ${ }^{\text {b1 }}$

By continuity considerations, the result extends to social welfare functions exhibiting a sufficiently high degree of inequality aversion (a sufficiently small value of $\rho$ ) and to the cases where there exists a sufficiently high correlation between height and skill (namely, for values of $\alpha_{H T}$ close to one and $\alpha_{H S}$ close to zero). This completes the proof. QED

\section{Caveat}

Crucially, note that the result does not extend to the case of high (but less than perfect) correlation, when the social welfare function is Rawlsian, as in such a case the welfare measure will not be continuous with respect to $\alpha_{H, T}$, at $\alpha_{H, T}=1$. To see this, note that for the case of perfect correlation between height and skill, the wage differential under affirmative action policy (as derived in section 2.1 in the text) is strictly positive and given by $\varepsilon=(\bar{w}-\underline{w}) / 2$. Under perfect correlation, the least advantaged individual in the economy (whose utility is being maximized) would be a low-skilled short worker. When the correlation is high (but less than perfect), there is a positive fraction of low-skilled tall workers in the economy. By virtue of the affirmative action policy, the most disadvantaged individuals in the economy in such a case would be the low-skilled tall

${ }^{b 1}$ Recall that the affirmative action equilibrium exists when the productivity difference between the two skill levels is sufficiently small. 
individuals, as their wage rate would be reduced (relative to the low-skilled short). Thus, there would be a discontinuous jump in the wage rate of the most disadvantaged individual (by the amount of $2 \varepsilon>0$ ), as we shift from the case of perfect correlation to the case of high (but less than perfect) correlation, hence a discontinuous jump in the welfare measure. Thus, the continuity consideration used in the proposition with respect to the correlation between skill and height would be invalid. In fact, affirmative action policy would result in a decrease in the welfare measure in the Rawlsian case, when $\alpha_{H, T}<1$. 


\section{References}

Akerlof, G. (1978). "The Economics of Tagging as Applied to the Optimal Income Tax," American Economic Review 68, 8-19.

Arrow, K. (1998). "What Has Economics to Say about Racial Discrimination?" Journal of Economic Perspectives 12, 91-100.

Bell, D. (1992). Faces at the Bottom of the Well: The Permanence of Racism. New York: Basic Books.

Bloch, F. (1994). Antidiscrimination Law and Minority Employment. Chicago: U. Chicago Press.

Chan, J. and Eyster, E. (2003). "Does Banning Affirmative Action Lower College Student Quality?” American Economic Review, 93, 858-872.

Cooter, R. (1994). “Market Affirmative Action,” San Diego Law Review 31, 133-168.

Darity W. and Frank, D. (2003). "The Economics of Reparations," American Economic Review, 93, 326-329.

Donohue, J. (1998). "Discrimination in Employment," The New Palgrave Dictionary of Economics and the Law 615, Peter Newman Edition.

Edley, C. (1996). Not All Black and White. New York: Hill and Wang.

Epstein, R. (1992). Forbidden Grounds: The Case Against Employment Discrimination Laws. Cambridge, NA: Harvard U. Press.

Fiss, O. (1976). “Groups and Equal Protection Clause,” Philosophy and Public Affairs $5(2), 107-177$.

Fryer, R. (2004). "Implicit Quotas,” working paper.

Fryer, R. and Levitt, S. (2004). "The Black-White Test Score Gap Through Third Grade," 
American Law and Economic Review (forthcoming).

Fryer, R. and Loury, G. (2005). "Affirmative Action and Its Mythology" Journal of Economic Perspectives, 19(3), 147-162.

Fryer, R., Loury, G. and Yuret, T. (2006). "An Economic Analysis of Color-Blind Affirmative Action," working paper.

Kull, A. (1994). "The Discrimination Shibboleth," San Diego Law Review, 31, 195-201.

Loury, G. (1977). "A Dynamic Theory of Racial Income Differences," Chap. 8. P. Wallace (ed), Women, Minorities and Employment Discrimination, Lexington Books, 153-186.

(1998). "Discrimination in the Post-Civil Rights Era: Beyond Market Interactions." Journal of Economic Perspectives, 12, 117-26.

Mirrlees, J. (1971). "An Exploration in the Theory of Optimum Income Taxation," Review of Economic Studies, 38, 175-208.

Parry \& Portney, Paul \& Harrington, Winston \& Gruenspecht (2003). "Policy Watch:

The Economics of Fuel Economy Standards," Journal of Economics Perspectives 17(4) 203-217.

Risse, M. and Zeckhauser, R. (2004). "Racial Profiling," Philosophy and Public Affairs $32,131-170$

Rubenfeld, J. (1997). "Affirmative Action," Yale Law Journal 107, 427-472.

Sadka, E. (1976). "On Income Distribution, Incentive Effects and Optimal Income Taxation," Review of Economic Studies, 43, 261-67.

Schuck, P. (2002). “Affirmative Action: Past, Present, and Future," Yale Law \& Policy Review 20, 1-96. 
Schuman, H, Steeh C., Bobo L. and Krysan M. (1997). Racial Attitudes in America: Trends and Interpretations, Harvard University Press.

Stiglitz, J. (1982). "Self Selection and Pareto Efficient Taxation", Journal of Public Economics, 17, 213-240.

Sunstein, C. (1994). "The Anticaste Principle," Michigan Law Review 92, 2410-2455. 


\section{CESifo Working Paper Series}

(for full list see www.cesifo-group.de)

1940 Monika Bütler and Michel André Maréchal, Framing Effects in Political Decision Making: Evidence from a Natural Voting Experiment, March 2007

1941 Giacomo Corneo and Olivier Jeanne, A Theory of Tolerance, March 2007

1942 Qing Hong and Michael Smart, In Praise of Tax Havens: International Tax Planning and Foreign Direct Investment, March 2007

1943 Yin-Wong Cheung, Dickson Tam and Matthew S. Yiu, Does the Chinese Interest Rate Follow the US Interest Rate?, March 2007

1944 Panu Poutvaara and Mikael Priks, Unemployment and Gang Crime: Could Prosperity Backfire?, March 2007

1945 Burkhard Heer, On the Modeling of the Income Distribution Business Cycle Dynamics, March 2007

1946 Christoph A. Schaltegger and Lars P. Feld, Are Fiscal Adjustments less Successful in Decentralized Governments?, March 2007

1947 Giovanni Facchini, Marcelo Olarreaga, Peri Silva and Gerald Willmann, Substitutability and Protectionism: Latin America's Trade Policy and Imports from China and India, March 2007

1948 C. Mirjam van Praag and Bernard M. S. van Praag, The Benefits of Being Economics Professor A (and not Z), March 2007

1949 Astrid Hopfensitz and Frans van Winden, Dynamic Choice, Independence and Emotions, March 2007

1950 Guglielmo Maria Caporale and Luis A. Gil-Alana, A Multivariate Long-Memory Model with Structural Breaks, March 2007

1951 Mattias Ganslandt and Keith E. Maskus, Wholesale Price Discrimination and Parallel Imports, March 2007

1952 Michela Redoano, Fiscal Interactions Among European Countries. Does the EU Matter?, March 2007

1953 Stefan C. Wolter, Rémy Hübschi and Matthias Müller, Push or Pull? An Empirical Analysis of the Demand for Individual Project Grants from the Swiss National Science Foundation, March 2007 
1954 Scott Alan Carson, African-American and White Inequality in the American South: Evidence from the $19^{\text {th }}$ Century Missouri State Prison, March 2007

1955 Peter Egger, Marko Koethenbuerger and Michael Smart, Do Fiscal Transfers Alleviate Business Tax Competition? Evidence from Germany, March 2007

1956 Panu Poutvaara and Lars-H. R. Siemers, Smoking and Social Interaction, March 2007

1957 Stephan Danninger and Fred Joutz, What Explains Germany's Rebounding Export Market Share?, March 2007

1958 Stefan Krasa and Mattias Polborn, Majority-efficiency and Competition-efficiency in a Binary Policy Model, March 2007

1959 Thiess Buettner and Georg Wamser, Intercompany Loans and Profit Shifting Evidence from Company-Level Data, March 2007

1960 Per Pettersson-Lidbom and Mikael Priks, Behavior under Social Pressure: Empty Italian Stadiums and Referee Bias, April 2007

1961 Balázs Égert and Carol S. Leonard, Dutch Disease Scare in Kazakhstan: Is it real?, April 2007

1962 Paul De Grauwe and Pablo Rovira Kaltwasser, Modeling Optimism and Pessimism in the Foreign Exchange Market, April 2007

1963 Volker Grossmann and Thomas M. Steger, Anti-Competitive Conduct, In-House R\&D, and Growth, April 2007

1964 Steven Brakman and Charles van Marrewijk, It's a Big World After All, April 2007

1965 Mauro Ghinamo, Paolo M. Panteghini and Federico Revelli, FDI Determination and Corporate Tax Competition in a Volatile World, April 2007

1966 Inés Macho-Stadler and David Pérez-Castrillo, Optimal Monitoring to Implement Clean Technologies when Pollution is Random, April 2007

1967 Thomas Eichner and Ruediger Pethig, Efficient $\mathrm{CO}_{2}$ Emissions Control with National Emissions Taxes and International Emissions Trading, April 2007

1968 Michela Redoano, Does Centralization Affect the Number and Size of Lobbies?, April 2007

1969 Christian Gollier, Intergenerational Risk-Sharing and Risk-Taking of a Pension Fund, April 2007

1970 Swapan K. Bhattacharya and Biswa N. Bhattacharyay, Gains and Losses of India-China Trade Cooperation - a Gravity Model Impact Analysis, April 2007

1971 Gerhard Illing, Financial Stability and Monetary Policy - A Framework, April 2007 
1972 Rainald Borck and Matthias Wrede, Commuting Subsidies with two Transport Modes, April 2007

1973 Frederick van der Ploeg, Prudent Budgetary Policy: Political Economy of Precautionary Taxation, April 2007

1974 Ben J. Heijdra and Ward E. Romp, Retirement, Pensions, and Ageing, April 2007

1975 Scott Alan Carson, Health during Industrialization: Evidence from the $19^{\text {th }}$ Century Pennsylvania State Prison System, April 2007

1976 Andreas Haufler and Ian Wooton, Competition for Firms in an Oligopolistic Industry: Do Firms or Countries Have to Pay?, April 2007

1977 Eckhard Janeba, Exports, Unemployment and the Welfare State, April 2007

1978 Gernot Doppelhofer and Melvyn Weeks, Jointness of Growth Determinants, April 2007

1979 Edith Sand and Assaf Razin, The Role of Immigration in Sustaining the Social Security System: A Political Economy Approach, April 2007

1980 Marco Pagano and Giovanni Immordino, Optimal Regulation of Auditing, May 2007

1981 Ludger Woessmann, Fundamental Determinants of School Efficiency and Equity: German States as a Microcosm for OECD Countries, May 2007

1982 Bas Jacobs, Real Options and Human Capital Investment, May 2007

1983 Steinar Holden and Fredrik Wulfsberg, Are Real Wages Rigid Downwards?, May 2007

1984 Cheng Hsiao, M. Hashem Pesaran and Andreas Pick, Diagnostic Tests of Cross Section Independence for Nonlinear Panel Data Models, May 2007

1985 Luis Otávio Façanha and Marcelo Resende, Hierarchical Structure in Brazilian Industrial Firms: An Econometric Study, May 2007

1986 Ondřej Schneider, The EU Budget Dispute - A Blessing in Disguise?, May2007

1987 Sascha O. Becker and Ludger Woessmann, Was Weber Wrong? A Human Capital Theory of Protestant Economic History, May 2007

1988 Erkki Koskela and Rune Stenbacka, Equilibrium Unemployment with Outsourcing and Wage Solidarity under Labour Market Imperfections, May 2007

1989 Guglielmo Maria Caporale, Juncal Cunado and Luis A. Gil-Alana, Deterministic versus Stochastic Seasonal Fractional Integration and Structural Breaks, May 2007

1990 Cláudia Costa Storti and Paul De Grauwe, Globalization and the Price Decline of Illicit Drugs, May 2007 
1991 Thomas Eichner and Ruediger Pethig, Pricing the Ecosystem and Taxing Ecosystem Services: A General Equilibrium Approach, May 2007

1992 Wladimir Raymond, Pierre Mohnen, Franz Palm and Sybrand Schim van der Loeff, The Behavior of the Maximum Likelihood Estimator of Dynamic Panel Data Sample Selection Models, May 2007

1993 Fahad Khalil, Jacques Lawarrée and Sungho Yun, Bribery vs. Extortion: Allowing the Lesser of two Evils, May 2007

1994 Thorvaldur Gylfason, The International Economics of Natural Resources and Growth, May 2007

1995 Catherine Roux and Thomas von Ungern-Sternberg, Leniency Programs in a Multimarket Setting: Amnesty Plus and Penalty Plus, May 2007

1996 J. Atsu Amegashie, Bazoumana Ouattara and Eric Strobl, Moral Hazard and the Composition of Transfers: Theory with an Application to Foreign Aid, May 2007

1997 Wolfgang Buchholz and Wolfgang Peters, Equal Sacrifice and Fair Burden Sharing in a Public Goods Economy, May 2007

1998 Robert S. Chirinko and Debdulal Mallick, The Fisher/Cobb-Douglas Paradox, Factor Shares, and Cointegration, May 2007

1999 Petra M. Geraats, Political Pressures and Monetary Mystique, May 2007

2000 Hartmut Egger and Udo Kreickemeier, Firm Heterogeneity and the Labour Market Effects of Trade Liberalisation, May 2007

2001 Andreas Freytag and Friedrich Schneider, Monetary Commitment, Institutional Constraints and Inflation: Empirical Evidence for OECD Countries since the 1970s, May 2007

2002 Niclas Berggren, Henrik Jordahl and Panu Poutvaara, The Looks of a Winner: Beauty, Gender, and Electoral Success, May 2007

2003 Tomer Blumkin, Yoram Margalioth and Efraim Sadka, Incorporating Affirmative Action into the Welfare State, May 2007 